\title{
Accessibility patterns of Istanbul's Hans region as a traditional urban trade district
}

\author{
M. Ozkan Ozbek \\ Department of City and Regional Planning, \\ Mimar Sinan Fine Arts University, Turkey
}

\begin{abstract}
This study aims to understand the determining factors on pedestrian flow based on sustainable urban patterns related to factors such as spatial configuration, attraction of opportunities, and topological issues (slope of the land) that affect traditional accessibility measures. In this context the space syntax theory and other morphological techniques present some measures that could aid improvement of the environmental quality of pedestrian accessibility as well as helping to understand the retail dynamics of Hans region.

The space syntax configurations are used here to make several important observations configurationally ones obtained through the axial map, land use effects and the pedestrian flow, slope degrees where the trade areas are more in demand, pieces of land where natural movement occurs in highly integrated zones.

Ten important trade axes are chosen where Han buildings are densely settled for spatial configurations since that area was found to be a highly integrated district in all historical peninsula's global integration analysis. Land use analyses have been conducted to understand the diversity of human activities. Second, weekday and weekend pedestrian counts have been recorded including children, teenage, young and old people without considering gender difference. Terrain slope is also an important factor for Hans region therefore slope measures have been calculated of these streets. Correlation analysis of pedestrian counts and the local integration values have been done to understand the relationship between them. The outcomes of this study reveals the role of pedestrian movement in traditional trade areas and integration measures in the network are measured and presented graphically. Keywords: accessibility, pedestrian flow, retail diversity, traditional settlements.
\end{abstract}




\section{Introduction}

The historical peninsula in Istanbul is a spatially important heritage site that offers us an ideal space due to the historical layouts and the presence of a wide variety of typology of grid structure and buildings.

Starting from the first settlement period, Golden Horn, as a sheltered and natural harbor, has been a decisive factor in Istanbul's history. Its convenient location for maritime trade, on the shores, harbors, docks and wharfs give opportunities to develop as a commercial center. From the beginning of the 15th century, Han buildings have been constructed on the roads that connect estuary ports to the city's commercial center, starting from Sarayburnu to Ayvansaray. By the end of the 18th century, Han district and shopping places were formed at the back of the port which served a large population of sailors and traders. Imported goods were also stored in the triangle of Bayezid Laleli-Eminönü. In the 19th century along with the innovations of westernization, there were significant changes in the region's architectural character. During this period, masonry shops and Han buildings were almost all built on a larger scale than before, using western styles which have changed the district's appearance. Over 500 years of continued commercial identity remains the same today.

Although structuring on a highly sloped topographical region, Han buildings have adapted to the topography with their organic plan schemes rather than geometric ones (Figure 1).

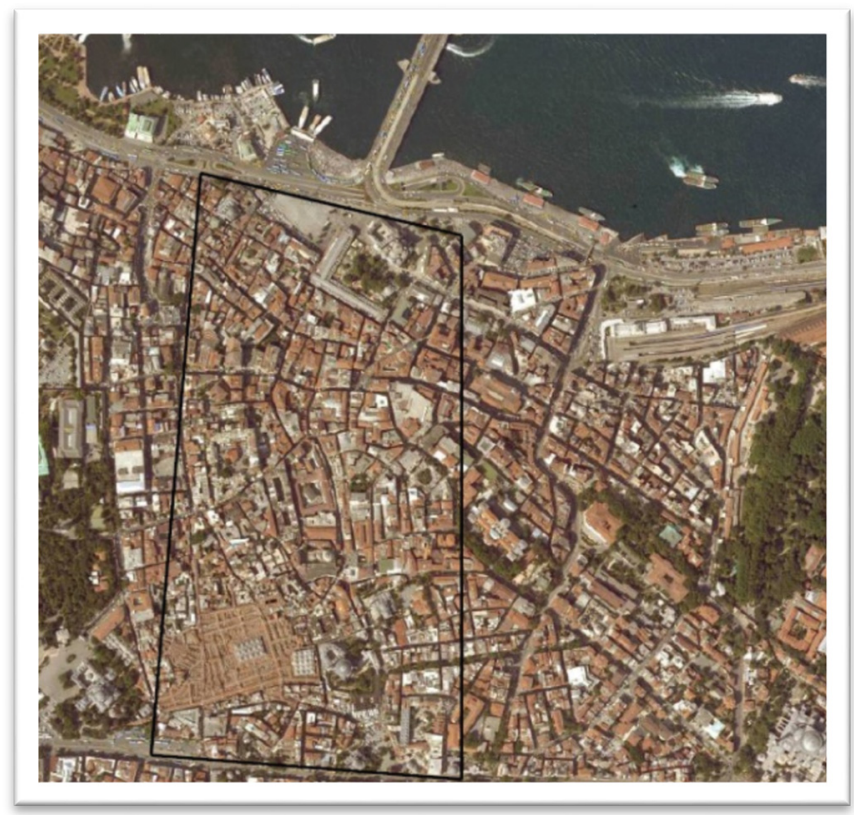

Figure 1: Hans region in peninsula. 
Architectural qualities of buildings, public spaces, and green areas are the key phenomena for environmental quality. According to Lynch [1], environmental quality depends on 'attractiveness' which underlies the identity of space. These attractive points, nodes, landmarks, etc. are based on pedestrian accessibility which can be noticed only on foot. That's why when we talk about pedestrian movement, spatial patterns take an important role to understand the nature of the urban structure.

The Hans region is a place where movement can be observed in a mass scale. Accessibility is mainly achieved by the design of urban patterns like streets and buildings. While analyzing accessibility in urban spaces, information such as land use degrees, movement patterns or morphological dimensions is incorporated. Such an overall review allows us to explore the relationship between space and its social agendas.

\section{Concepts and method}

This research has been developed over the morphological and topological layouts of Hans's region of Istanbul. This paper analyzes the pedestrian flow to understand the retail dynamics and integration measures which are often argued as prediction of movement capacity. Accessibility patterns which can be defined as natural movement can be the key phenomena in this research regarding the slope of the streets which really have impacts on this urban grid.

Natural movement has come to light as a form and empirical phenomenon thought. This application of new techniques of configurational analysis came to be known as space syntax to the analysis of the local and structure of urban grid [2].

When we talk about accessibility in urban areas, spatial integration analysis becomes useful as introduced by Hillier and Hanson in 1984 [3]. Integration analysis based on axial lines drawn on the map where each axial line represents a visual point and physical access. Accessibility can be measured from these axial lines which are called integration value of each line.

Spatial integration accessibility is using a spatial representation called axial line and the topological distance between axial lines are based on the number of steps. These steps are formed from one line to the other by the junction of the axial line and the metric radii will differ by routes and the trips' destinations [4].

Integration has been proved that it is correlated with pedestrian movement and their behavioral aspects. Such behaviors of human beings are related to the structure of urban form and can be measured from axial maps.

Accessibility is related to pedestrian movement. All direct relations, activities such as trade, social interactions or architectural awareness exist on streets. Quality of architecture and public spaces of urban areas take a major role in sustaining the accessibility of pedestrians, and thus the urban landscape itself [5].

What is proposed in this paper is to examine spatial morphologic patterns and to incorporate them into space syntax research tools as a way to evaluate integration values. Such an observation will ultimately pave the way to determine 
whether there is a correlation between topology/land use and accessibility in traditional retail zone of Hans region.

\section{Case study}

\subsection{A quick overview to spatial history of Hans region in historical peninsula}

Historical peninsula is probably one of the most spectacular places that includes important historical artifacts and trade axes called Han district. Since the 15th century, Han district remains an important venue to trace the rise of trade formed by its topographic space. This spatial and social continuity has increased the scholarly merit of this place; as shown in Figure 2, Han buildings reveal a significant pattern of spatial articulation created over the course of centuries.

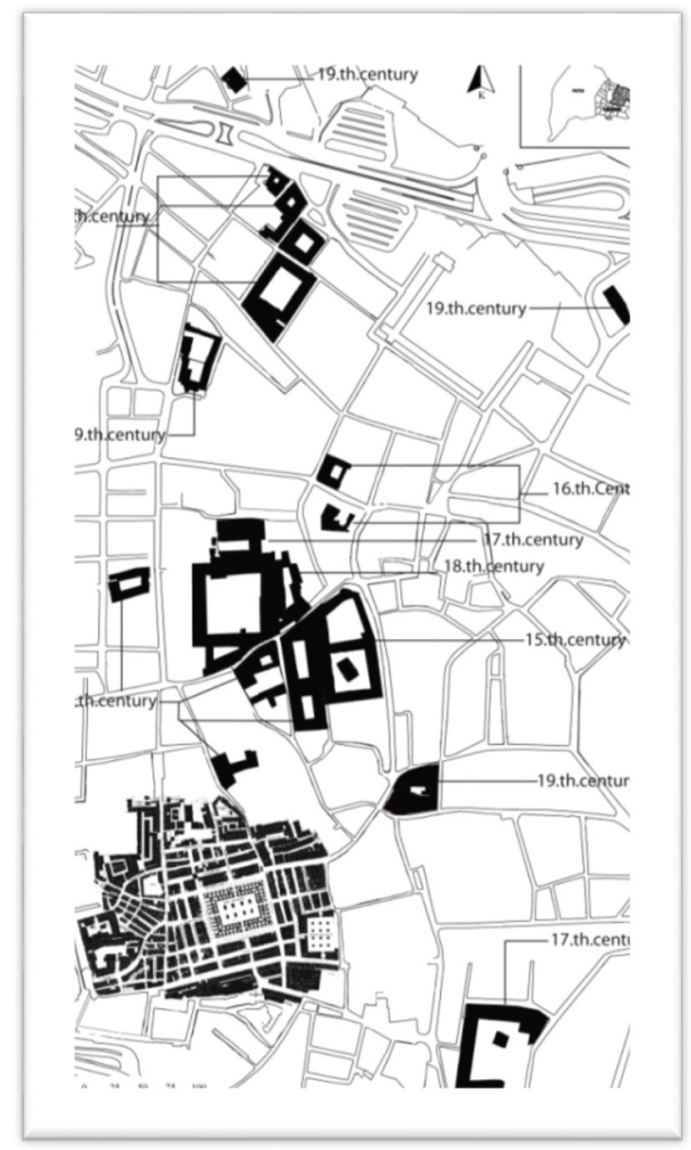

Figure 2: Han buildings over the centuries. 
Capital History of Istanbul had begun 65 years before the division of Roman Empire into east and west. By the request of Great Constantine, Byzantium (also known as "Nova Roma"), became the capital of Roman Empire in the year of 330 AC. After the death of the emperor, the city's name was changed to Constantinople in his memory. Constantinople had become the capital of the state which later was called "Byzantine Empire" in 395. Due to its rapidly growing population, major ports and warehouses were built in due course.

After the conquest of Constantinople in May 1453 by Ottomans, this new era marked itself in the port and harbor activities. Trade axes had sustained their important role in the region. In this process commercial activities had intensified in the current Grand Bazaar area and Bazaars and Han Buildings gave shape to the central bazaar area.

Hans region transformed into a city center because of the commercial facilities that keeps money inside and thus ensures pedestrian movement is kept alive. We need to look at these Han buildings not just as spaces that accommodate traders but also as venues that store goods, offices, and therefore keep surroundings alive by the relations with other regions.

Dominant phenomenon of commercial identity of Roman, Byzantine and Ottoman periods would have fed shopping axes system which continues throughout the periods. One of these main axes was Divanyolu in Ottoman era and Mese Road in Byzantine time which is now called as Uzunçarşı in Hans region which is shown in Figure 3.

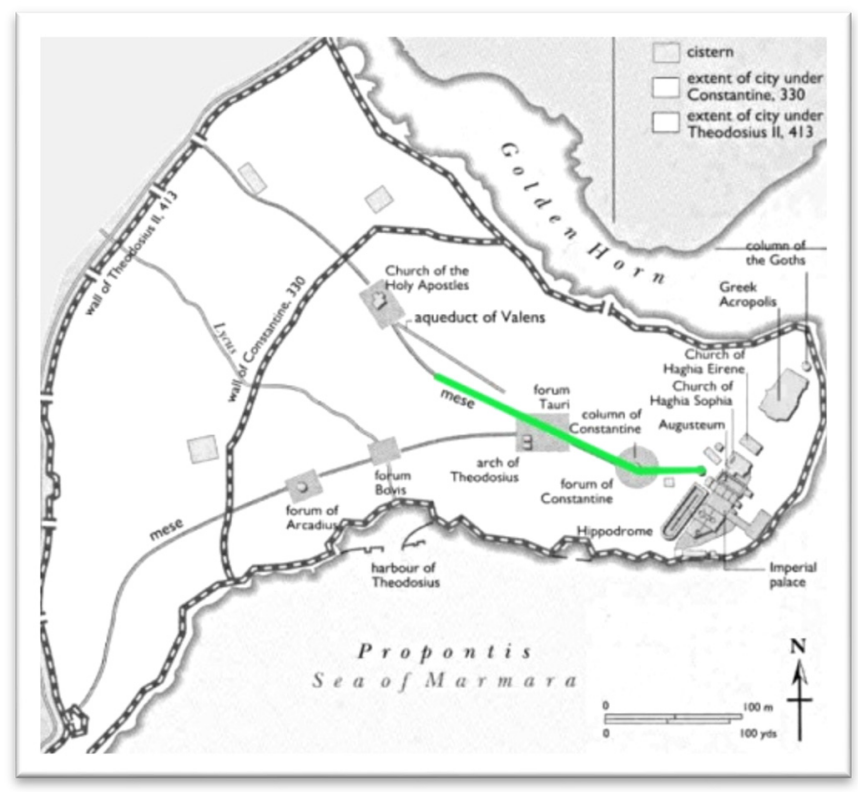

Figure 3: Mese Road overlapped with Divanyolu (in green) (http://indiciumlevis.blogspot.com.tr/2012/11/mese-divanyolu.html). 


\subsection{Axial analysis of historical peninsula}

In space syntax analyses axial maps are fundamental representations to conduct analysis. Axial lines are the sight lines drawn from each open public space one by one. In axial maps, integration degree increases by the number of intersections of axial lines. Most integrated parts are graphically represented with black; conversely, least integrated places are marked with white (or from red to green in general space syntax presentations). From this point of view, axial maps of historical peninsula are drawn to analyze its integration measures both in global and local scales. Before focusing on Hans region spatially, analyzing all peninsula space is an important criterion to see how spaces are integrated or segregated. In $\mathrm{Rn}$ (global) analysis we can come to a solution like it's more integrated in its central area comparing to R3 (local) analysis. In R3 we can observe that spaces are less densely integrated through eastern parts that we can't observe in Rn (Figure 4). As mentioned before, in the research of Kubat analyzed in 1999 [6], considering R3 and Rn analysis, peninsula has more Christian-Roman-European characteristics than Islamic where we can observe it in a Y shape spine which still carries the traces from Byzantine era.

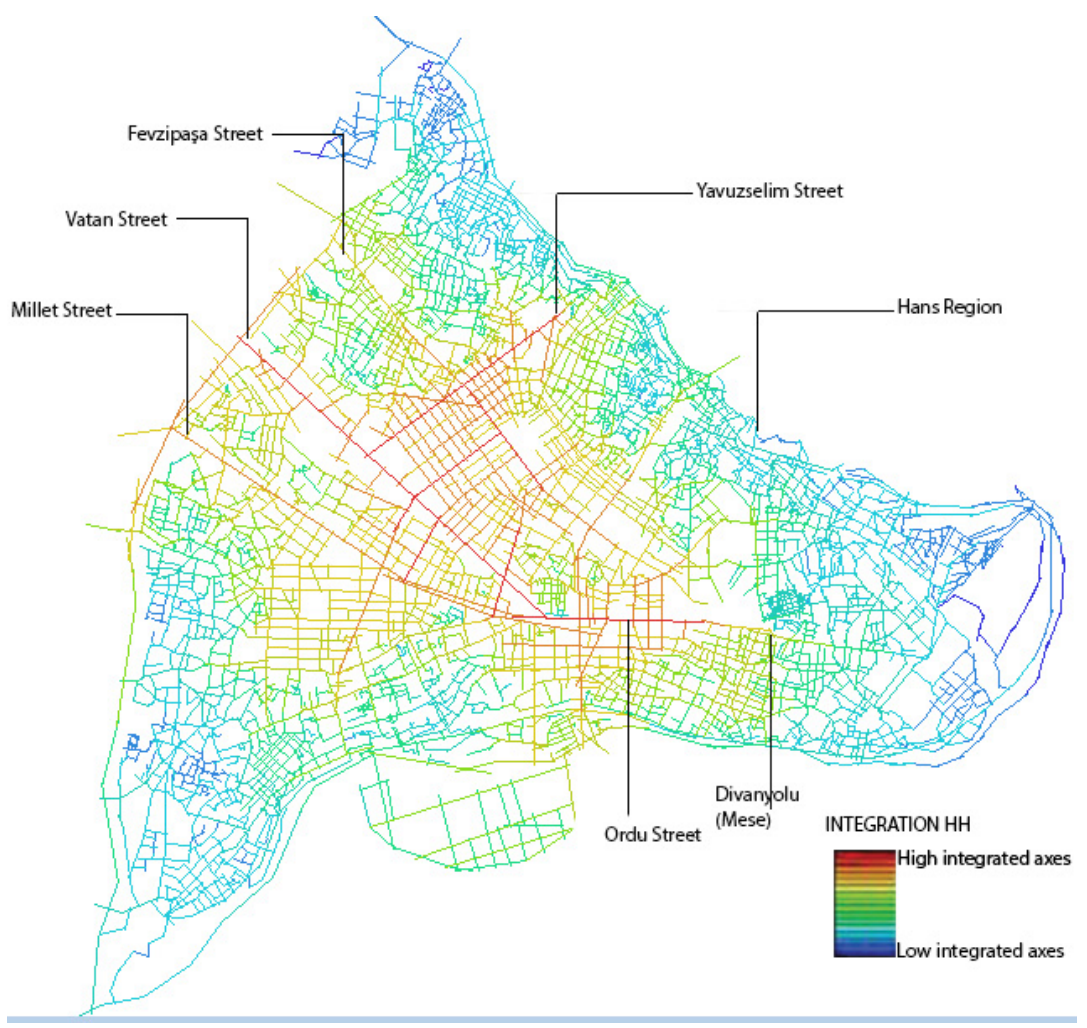

Figure 4: Local and global integrations of historical peninsula. 


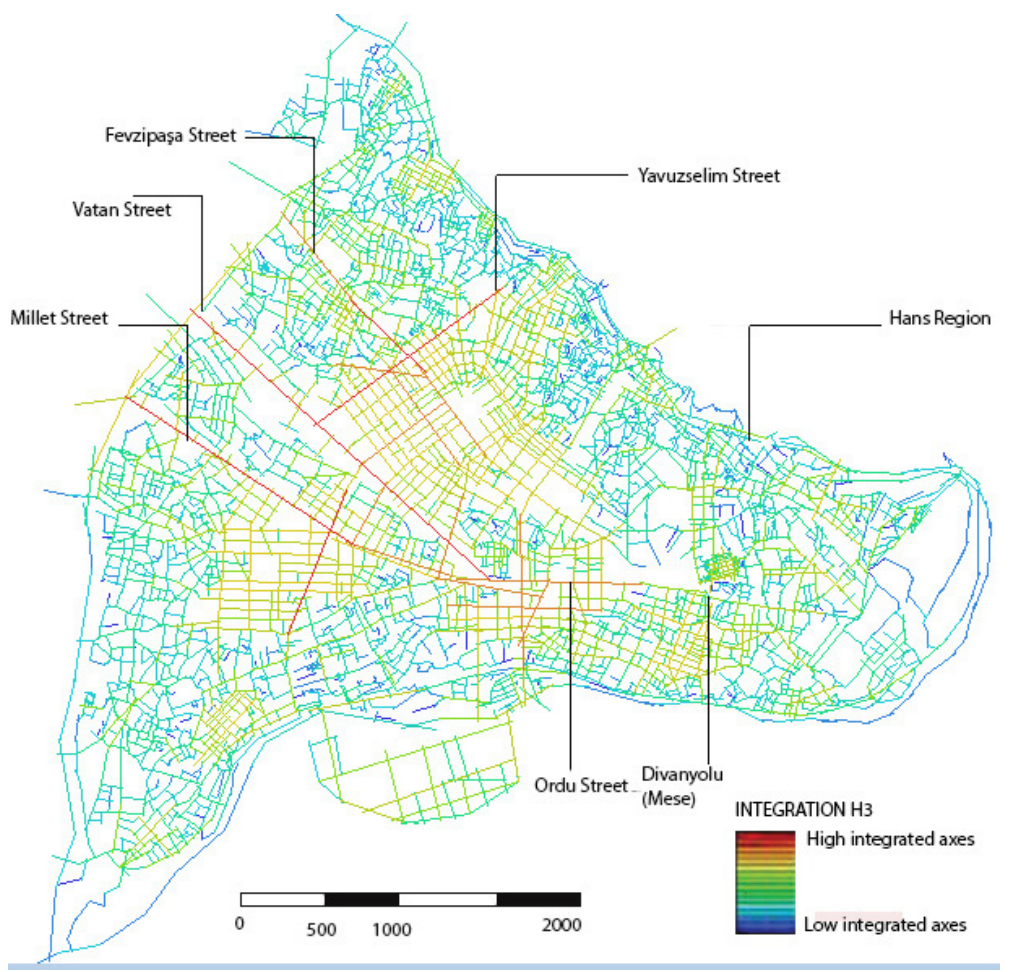

Figure 4: Continued.

\subsection{Spatial analysis in Hans zone}

In research area 10, streets are chosen where Han buildings are heavily dense. In March 2013,pedestrian counts were made on chosen streets both weekdays and weekends starting from $8 \mathrm{am}$ to $8 \mathrm{pm}$ for 5 minutes in every hour considering children, teenage, young and old people, but ignoring their gender types. In Figure 5 Han buildings can be seen with the axial map overlaid on it.

In the pedestrian counts, every day activities of people were observed considering land use patterns. In this historic core, Hans has special form that carries people to their inner courtyards where commercial activities ensue. (Figure 6).

In order to understand the effects of slope scores on movement, correlation analysis has been done between local integration values, pedestrian counts and the percentage of streets slopes.

For those who responded to this survey higher local integration scores were correlated with higher pedestrian count scores $r=0.70$ for weekdays with large effect and $r=0.20$ for weekends. When we correlate slope degree and R3 scores it results as $r=0.10$ which means a positive relation with each other but with small effect. 


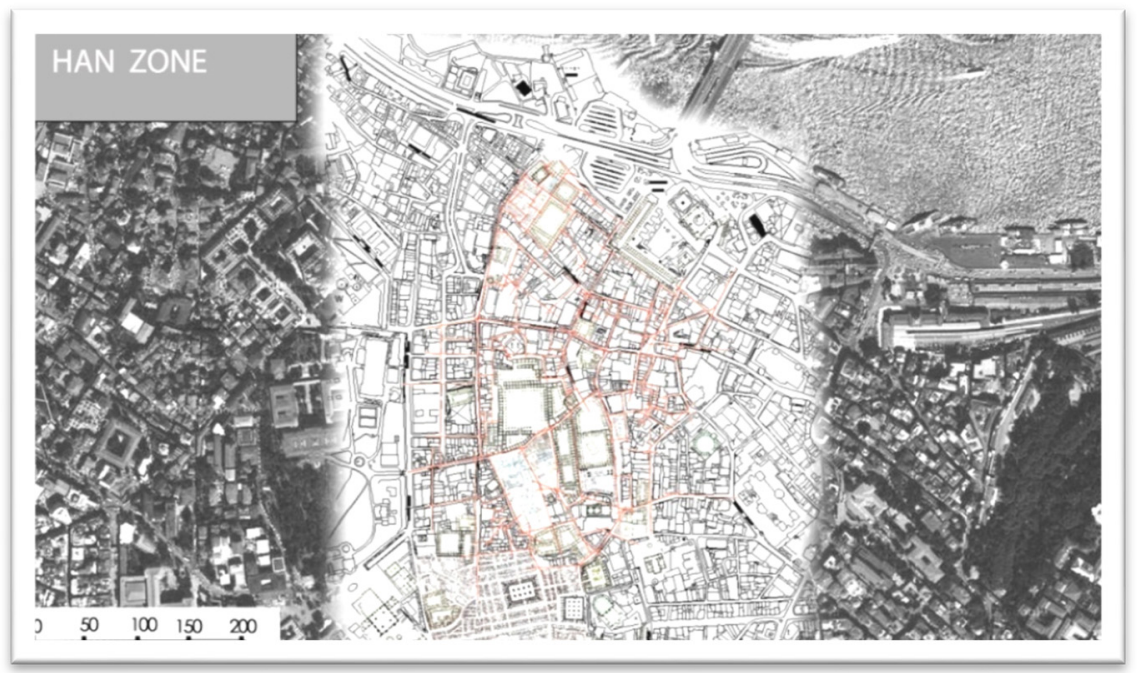

Figure 5: Axial map with Hans.

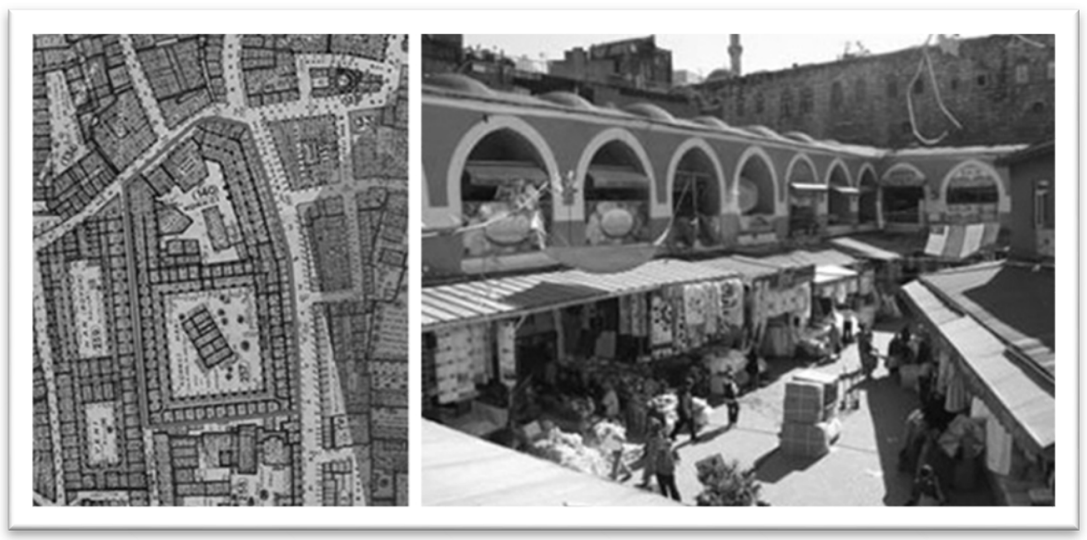

Figure 6: Kurkcu Han built in the $15^{\text {th }}$ century. On the left is the Pervititch Map view in 1923. On the right its inner space with commercial facilities today.

In urban systems configuration is the primary generator of pedestrian movement patterns [2]. When we first take a look at the results of local integration analysis, Vasif Cinar Street (Figure 7) comes out as the most integrated street. In the pedestrian counts analysis this street also carries the most pedestrians through the rest of the system and its slope degree is $5.40 \%$ but this doesn't mean that there is a strong relation between slope and the rest because there are streets with less 
flow and nearly no slope at all. This pattern goes through the streets with same rages until the least integrated and less pedestrian counts shown in Figure 8 and in Table 1 with their scores.
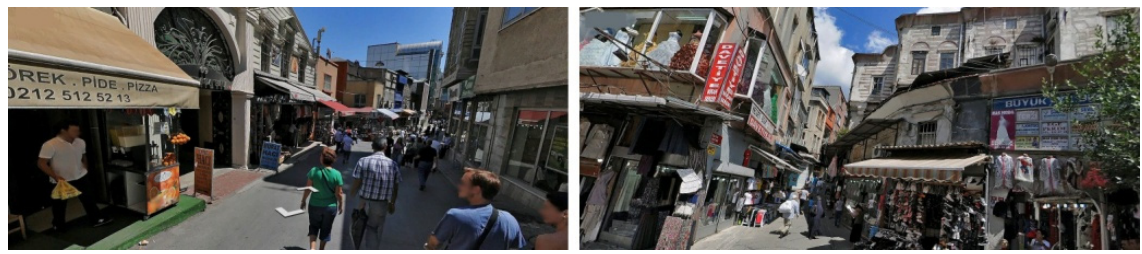

Figure 7: Vasif Cinar as most integrated Street on the left Sultan Mektebi Street as least integrated on the right.

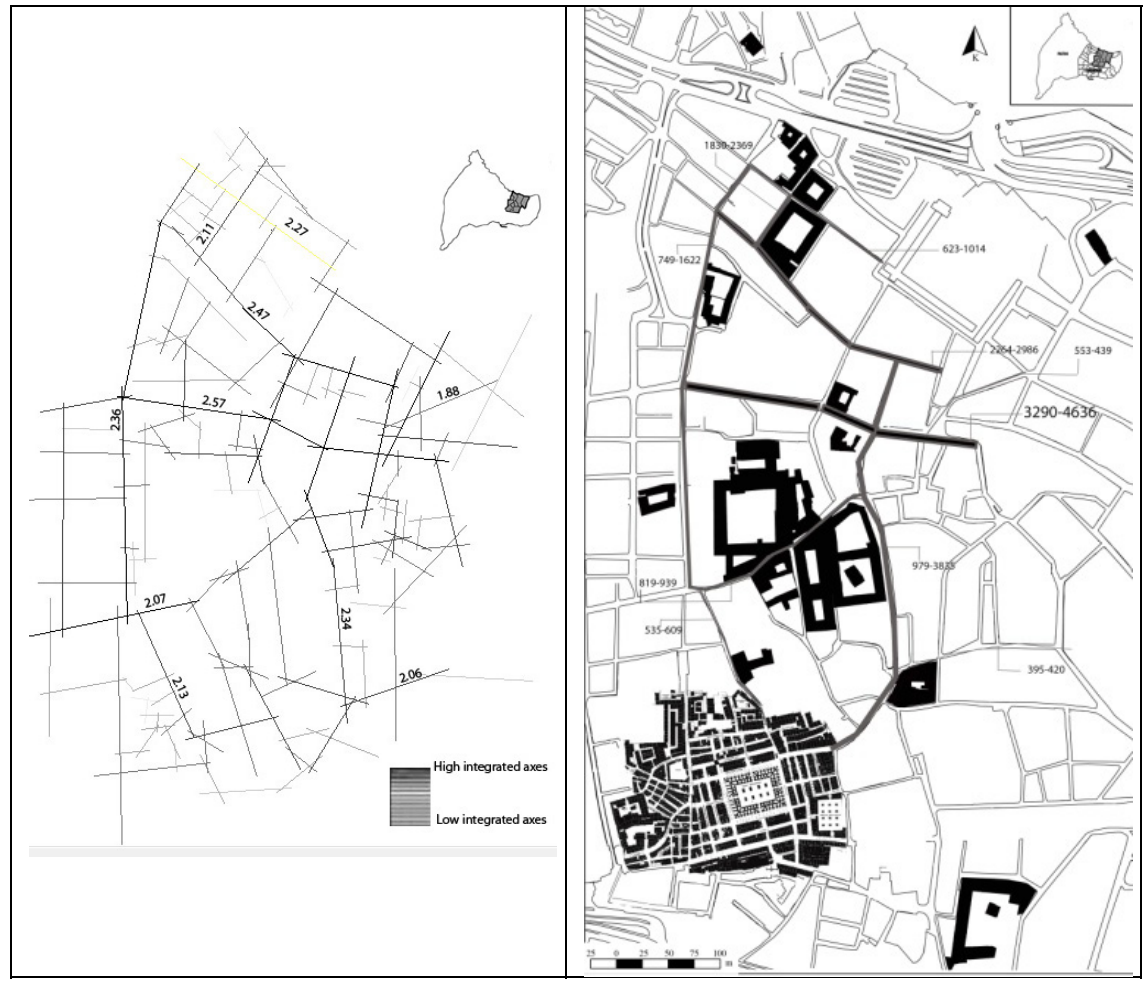

Figure 8: On the left R3 analysis of the area with their measures on axes. On the right streets shown with sum of pedestrian counts both in weekdays and weekends. 
Table 1: Mean, minimum and maximum scores of analysis of pedestrian counts, local integration and slope degrees.

\begin{tabular}{ccccccccc}
\hline Weekdays & & Weekends & \multicolumn{3}{c}{ HHR3 } & \multicolumn{3}{c}{$\begin{array}{c}\text { Slope } \\
\text { Degree }\end{array}$} \\
\hline & & & & & & & \\
Mean & 1203.7 & Mean & 1886.9 & Mean & 2.226 & Mean & 0.0644 \\
Minimum & 395 & Minimum & 420 & Minimum & 1.88 & Minimum & 0 \\
Maximum & 3290 & Maximum & 4636 & Maximum & 2.57 & Maximum & 0.2 \\
\hline
\end{tabular}

\section{Results and conclusion}

The objective of this research was to study the background of this unique structure of Hans region and how it has sustained its commercial identity for more than 700 years. First of all Han buildings themselves are important architectural heritages which define street surfaces with their continuity of mass stoned facades, starting from sea side (or port Neorion from antiquity) to the Grand Bazaar area. Also their courtyard plans attract pedestrians into different public spaces, spaces that can be defined as extensions of streets and commercial facilities. Vasıf Çınar Street has the maximum accessibility measures which suggests that the maximum rank of movement is also located in the center part of the zone.

It is not surprising to find that streets which are well-integrated in the system and which exhibit significant movement also become prominent locations for retail [7].Spatial syntax measures have an important effect on research because they allow us to understand the influence of the urban layout on natural movement. For instance, some of the spaces are well-connected (with a high degree of connectivity), while others are less so. This is the fundamental principle of space syntax [8]. From this view, sloppy topography which can be a challenging route from time to time, needed to be analyzed to see if there is a correlation between slope degrees of streets, their integration measures and with the flow. Depending on correlation analysis it has been measured that slope degrees don't link directly to usage of space and people as far as movement and integration are concerned. As mentioned by Karimi [9], because there is a direct relationship between spatial configuration and urban functions, analysis of the spatial configuration provides a powerful tool for designing, shaping, maintaining and altering urban functions.

\section{Acknowledgement}

This study is part of my research project called "Hans region and its movement economy effects" in MSGSU Scientific Researches Department in 2014 with the help of my precious students for area studies from my lecture called "Spatial Analysis Techniques". 


\section{References}

[1] Lynch, K., "Image of the city", Cambridge Massachusetts: MIT Press, 1988.

[2] Hillier, B., Penn, A., Hanson, J., Grajewski, T., Xu, J., "Natural movement: or, configuration and attraction in urban pedestrian movement", Environment and Planning B: Planning and Design, vol. 20, pp. 29-66, 1993.

[3] Hillier, B., Hanson, J., "Social Logic of Space", Cambridge University Press, 1984.

[4] Charalambous, N., Mavridou, M., "Space Syntax: Spatial Integration Accessibility and Angular Segment Analysis by Metric Distance (ASAMeD), http://www.accessibilityplanning.eu/wpcontent/uploads/2013/01/3ASAMeD -R.pdf 2012.

[5] Ozbek, M., Gulec, Ozer, D., "Spatial Integration and Accessibility Considering Urban Sustainability Patterns: Historical Islands of Istanbul” The Sustainable City IX (2 Volume Set), WIT Press, Paper DOI: 10.2495/SC141402, 2014.

[6] Kubat, A.S., "The Morphological History of Istanbul", Urban Morphology, 1999, 3(1), pp. 28-41.

[7] Marcus L., "Spatial Capital and How to measure it" 6th. Space Syntax Symposium, Istanbul 2007.

[8] Hillier B., "Space is a Machine" Cambridge: Cambridge University Press, 1996.

[9] Karimi K., "Space Syntax Methodology: A Configurational, Analytical Framework of Urban Design" URBAN DESIGN International (2012) 17, pp. 297-318. doi:10.1057/udi.2012.19; published online 26 September 2012 http://indicium-levis.blogspot.com.tr/2012/11/mese-divanyolu.html. 